\title{
INTEGRAÇÃO: PALAVRA PARA QUEM QUISER VIVER O FUTURO!
}

\author{
INTEGRATION: word to live the future!
}

Cenário: Munique, dezembro de 2000 com muita neve e muito frio!

Evento: Congresso Mundial de Alta Tecnologia em Cirurgia

Convidado especial do evento: Richard M. Satava, Professor do Departamento de Cirurgia da Universidade de Washington, Seatle, USA.

Atividade principal do convidado: robótica, inteligência artificial, medicina aeroespacial e alta tecnologia aplicada à cirurgia.
W sse interessante congresso, ao raiar do século XXI, se propunha a descortinar o que aconteceria à cirurgia nas próximas décadas. Foi a primeira vez que vi e manipulei o robô Da Vinci - fantástico instrumento para procedimentos cirúrgicos à distância e o prenúncio do atendimento médico nas viagens interplanetárias -, dentre outras novidades não menos importantes e que fizeram berço para o grande avanço tecnológico que vivemos hoje na cirurgia moderna .

Além do visual sempre agradável para um habitante dos trópicos - neve em grande escala, divertida no começo ao tirar o gelo do carro pela primeira vez, mas muito chata ao passar dos dias -, o evento nos fez conhecer o Prof. Richard Satava, expoente da medicina tecnológica e consultor da NASA para assuntos médicos nas naves espaciais. Além

de ensinamentos nessa área, contando suas experiências e pesquisas, filosofou várias vezes sobre como um cidadão deve comporta-se se quiser viver o futuro no século que se iniciava. De suas interessantíssimas narrativas, duas expressões me marcaram: "Era da Informação e Integração".

Com a "Era da Informação" quis ele dizer que a base de todo o desenvolvimento humano se dará pela coleta de dados informatizada e sua interpretação. A "Era da Tecnologia" que fez desenvolver os excelentes computadores que hoje manipulamos e seus mais diversos derivativos, são coisas do século passado e que o caracterizaram. É claro que sem eles nós não estaríamos onde hoje estamos, portanto não devemos diminuir sua importância. Mas o conhecimento e manuseio da informação é que fará a humanidade galgar as grandezas que hoje são distantes e aparentemente intransponíveis.

Com a "Integração" quis ele dizer que o conhecimento e a tecnologia ficaram grandes demais para que grupos ou pessoas possam tê-las sob seu domínio intelectual isolado. Não temos mais condições de dominar o todo, mas sim suas partes. O todo somente será conseguido com a união dessas partes, ou seja, INTEGRAÇÃO ENTRE AS PARTES.

É assim que o Colégio Brasileiro de Cirurgia Digestiva tem pensado e agido. No que diz respeito às suas publicações e, entendendo que a integração é a palavra da inteligência na atualidade, procurou aproximar-se das associações congêneres e estimulou-as a somar forças em vez de competir no isolamento na divulgação de seus trabalhos. Os Arquivos Brasileiros de Cirurgia Digestiva ABCD abriu-se e integrou-se com Associação Brasileira de Câncer Gástrico, Capítulo Brasileiro da International Hepato-Pancreato-Biliary Association, Grupo de Estudos das Doenças do Pâncreas e Sociedade Brasileira de Cirurgia Bariátrica e Metabólica dando mostras que aceitar este modo de pensar é a alavanca mestra para chegar ao futuro com galhardia e grande sucesso.

Já tendo ultrapassado o difícil patamar de se transformar em periódico de visibilidade internacional, ou seja, estar na base SciELO que conseguiu ingressar no ano passado, agora está em nova fase. Nela pretende melhorar a qualidade de seus artigos através de pesquisas não só encaminhadas por membros da comunidade científica ligados ao CBCD, mas também por seus quatro novos parceiros. Fortalecendo nosso periódico estaremos também contribuindo para a melhoria de qualidade da produção brasileira, que já está na $13^{a}$. posição no ranking mundial em número, mas precisa aumentar sua qualidade. Teremos mais um periódico brasileiro de qualidade internacional para nos orgulhar em mencionar em nossas referências. Estaremos fortalecendo nossas publicações com o aumento do valor das revistas médicas brasileiras. Isto é ser brasileiro: engrandecer nossas revistas e transformá-las referenciais quanto aos indicadores de qualidade do cenário internacional. Não empobrecer nossos periódicos enviando "para fora"(e às vezes dizendo isto com orgulho!) o que achamos de melhor. $\mathrm{O} A B C D$ está dando, com esta demonstração de integração e força, oportunidade de engrandecer nosso País e fazê-lo mais respeitável no aspecto científico, como já o é em outras atividades 
do conhecimento e desenvolvimento humano.

Além disso, a partir de 2010 ele está com nova e moderna forma, acompanhando também as tendências mundiais de editoração de periódicos científicos. Acatou todas as considerações dos consultores que compõem o Comitê Consultivo da SciELO que, em intenso trabalho de ajuda, sugeriram modificações que estão incorporadas nessa nova forma de publicar nossa revista.

Assim, quer o CBCD agradecer aos Prof. Drs. José Jukemura, Ricardo Cohen, Thomas Zego, e Bruno Zilberstein representantes de nossos novos parceiros pelo crédito de confiança em nossa revista, à BIREME na pessoa de seu Presidente Prof. Dr. Abel Laerte Packer, ao Comitê Consultivo da SciELO nas pessoas dos Profs. Drs. Rogério Meneghini e Lewis J. Greene, ao corpo de técnicos da SciELO nas pessoas das Profas. Adriana Luccisano, Fabiana Ramos Montanari e Denise Nogueira, pelo constante apoio e voto de credibilidade em nossos propósitos, ajudando-nos a chegar à indexação que orgulha todos os brasileiros. Isto é INTEGRAÇÃO e com ela chegaremos ao futuro com engrandecimento de todos da comunidade científica e de nosso País.

Diretoria do CBCD 2009/2010

(Nelson Adami Andreollo, Ivan Cecconello, Cláudio José Caldas Bresciani, Nicolau Gregori Czezcko, Bruno Zilberstein, Carlos Eduardo Jacob, Osvaldo Malafaia, Jurandir Marcondes Ribas Filho e Luiz Roberto Lopes) 